\title{
A Review and Prospects of Project Investment Risk
}

\author{
Cheng Li, Shenxi Miao* \\ Pan-Asia Business School, Yunnan Normal University \\ Kunming 650000, China \\ lichengcg@163.com,941808030@qq.com
}

\begin{abstract}
The prevention and management of project investment risk is an inevitable important issue in the development of enterprises. The management of project investment risk is a research hotspot of risk management in recent years. This paper uses the literature analysis method to sort out the domestic literature, and puts forward three factors: the national macro level, the enterprise project investment risk mechanism level and the investment manager level, which affect the investment risk of the enterprise. As four commonly used project investment risk assessment methods, the sensitivity analysis method, the breakeven balance, Monte Carlo simulation and real options are compared and then the advantages and disadvantages of each method are analyzed. Finally, based on the influencing factors and evaluation methods of project investment risk, the research prospects of further reducing project investment risk are proposed.
\end{abstract}

Key words-Project investment risk, Risk assessment, Risk control, Analysis of risk

\section{INTRODUCTION}

When selecting an investment project, the company will consider the project's revenue first and measure the project risk. The investment risk of the project is an important part that directly affects the investment results of the enterprise, including decision risk, research risk, cost-benefit risk and so on in the whole investment process. The existence of project investment risks has led investors to under-control the project, and the expected return is uncertain. Because the project investment process includes four stages of financing, investment, management and exit (W. H. Lin, 2018), it is a dynamic process. And the overall macro environment, the invested enterprise and the investment enterprise itself are constantly changing, once there is any factor. Changes will directly affect the final result, so the project managers must make adjustments and changes at any time based on these changes to ensure the project investment. Therefore, it is important to measure the investment risks when conducting an investment project. Investors should focus on the factors that cause the project risk to rise, and avoid the corresponding risks as much as possible to obtain the maximum investment income.

This paper will analyze the main reasons for the existence of investment risks from the factors affecting project investment risk. Explain and analyze the advantages and disadvantages of the four methods of project investment risk assessment that are currently used by enterprises. Finally,

* Corresponding author: 941808030@qq.com based on the influencing factors and evaluation methods of project investment risk, the prospect of further research on project investment risk is proposed.

\section{FACTORS AFFECTING THE INVESTMENT RISK OF}

\section{ENTERPRISE PROJECTS}

\section{A. National macro level}

In a market economy, a company's project investment behavior is affected by some complex external factors. Changes in the national macro economy are also bound to have a profound impact on the project investment behavior of enterprises, and this impact is inevitable. The macroeconomic impact on corporate project investment mainly includes: uncertainty of environmental changes, imperfections of national policies and laws, changes in industry competition, etc., stimulated by these factors, the risk tolerance of enterprise investment, capital investment scope and so on may fall, and enterprises will face investment risks. At the same time, when enterprises invest in projects, there will inevitably be information asymmetry between project investment and changes of market economy. As it is unable to adjust in time according to the changes in the market environment, the risks of investment will increase. The problem caused by such unreasonable operation of the market economy is the risk that enterprises are difficult to avoid. And the risk of competition in the same industry is also having a huge impact, such an environment increases the risk of different degrees of investment in the project (H. Y. Shen, 2015).

\section{B. Enterprise project investment risk mechanism}

As enterprises continue to invest outwards, expand the breadth, time of investment, and capital investment, the risk of investment must be paid attention to by enterprises. However, at this stage, due to the imperfection of laws, and the profit-seeking and blindness of enterprises, many enterprises have not established corresponding risk management mechanisms in enterprises or projects. Investors cannot do what they have to in all aspects of project investment. In the whole process of project investment, the project planning and risk analysis are needed in the early stage. In the medium term, the project changes should be controlled, the project risks should be prevented and managed, and the funds should be recovered and the project evaluated later. This is the complete management of the project. Process and risk prevention and control. At the same time, if multiple projects are planned, the choice of appropriate project promotion strategies will be influenced by the internal and external environment, as well as a high degree of complexity (C. C. Chang,2006). However, the risk management mechanism is not in place, which makes the investment between the company and the market change out of line, and is out of touch with the company's own business 
conditions (L. W. Zhang, 2019). Then, once there is a risk beyond the estimated, it will cause a serious blow to the project.

\section{The risk awareness and preferences of managers}

When investing in projects, there are often investors who are aggressive, blindly pursuing high returns and disregarding high risks. Risk management and control of a project is a complex and important task. As an investment manager, certain capabilities of relevant professionalism, familiarity with the industry and projects, using corresponding investment risk measurement methods and tools to estimate risks and timely operation of the project must be needed. However, the investment risk management of many enterprises is still at the accounting level (J. Zhao, 2018). The risk awareness of financial personnel is relatively weak. The level of professional knowledge required for risk management methods is lacking. It is impossible to use relevant tools and models for evaluation and control. Non-standard, inadequate, and irrational aspects of goal setting, risk aversion, and post-regulation all increase the financial risk of investment projects (B. Wang, 2019). Therefore, in this respect, if the project investors can have a high level of professionalism and experience, it is believed that the risk control and investment of the project can provide more reasonable and scientific advice.

\section{ANALYSIS METHOD OF PROJECT RISK}

\section{A. Sensitivity analysis}

Sensitivity analysis is used to detect how sensitive the net present value is when the factors affecting the project change. The standard sensitivity analysis calculates the net present value that a variable may estimate under different conditions while other variables remain the same. Of course, it is also possible to simultaneously change a number of factors to determine impacts on the net present value.

The advantage of sensitivity analysis is that it avoids overly optimistic estimates of the project's net present value results. In terms of the influencing factors of the project, it can also tell investors where to collect more information, and how many factors may have a potential impact on the project, so that investors and managers have a more comprehensive grasp of the potential risks of the project. The disadvantage of sensitivity analysis is that many influencing factors may be interactive, and sensitivity analysis is hard to determine the possible impacts of these interrelated factors on the project. In addition, this method does not consider the probability of influencing factors, and there is considerable subjective randomness in the analysis and calculation (C. Y. Xia, 2012), which affects its scientific evaluation of risk assessment.

\section{B. Breakeven point}

The break-even point is the amount of sales required to determine the company's breakeven, divided into the breakeven point of the accountant and the breakeven point of the net present value. According to whether there is a linear relationship between production cost, sales revenue and output, the break-even analysis can be divided into linear break-even analysis and nonlinear break-even analysis (C. Y. Xia, 2012). The break-even point of accounting needs to consider the variable cost. The unit price minus the variable cost can compensate the sum of the fixed cost and depreciation generated by the enterprise. The required product quantity is the break-even point of accounting profit. The breakeven point of the present value needs to calculate the approximate annual cost of the initial investment amount. Under the premise of considering the tax shield effect of depreciation and cost, the marginal income of the unit product is calculated to make up the annual average cost and the fixed cost minus the amount of sales required for depreciation.

The break-even point method is relatively simple, which analyzes the impact of variables on the return of the project. It is a clearer risk assessment method that allows investors to clearly understand the key issues of risk assessment for project recovery costs under the influence of existing factors. However, it is hard to meet the diversified analysis needs of investors for project risk assessment.

\section{Monte Carlo Simulation}

Monte Carlo simulation is one of the analytical tools for project investment risk and has a wide range of applications. By analyzing the factors affecting the project's income, managers can use these factors as variables to construct a net present value model, then determine the probability range of each variable, and take random values within the possible probability range of the variable, the calculation result can be obtained finally. This is a result of the first value. The core of Monte Carlo simulation is to estimate the probability of future cash flow by repeating a large number of simulations.

Monte Carlo simulation relies on a computer programming language to enable fast and large-scale simulation needs. It is an effective analytical tool for project investment risk measurement. Monte Carlo simulation can effectively predict the existence of risk and the probability of occurrence of risk, thus improving the scientific of decision-making, which has great practical value (Y. Zhang, 2007). The advantage is that it can effectively simulate the future profitability of the project, it mainly targets the project's net present value, internal rate of return and other conventional income measurement indicators, and evaluates the project through the results, which has a strong practical significance for measuring and predicting the probability of risk. Although it has scientific advantages compared with the above-mentioned project risk assessment methods, due to the complicated calculation method, it requires a certain computer programming basis to carry out a large number of random simulations, and calculation model of net present value is needed, so this method is less used by enterprises.

\section{Real option}

Real option is the power of investors to make investment decisions in an uncertain environment when making investment decisions. The most commonly used real option is the binomial model, which has a probabilistic estimate of the possible return on investment of the project at different decision time nodes. The decision opportunities appearing at each node will extend the decision time node to make investment choices. This creates a network of changes in project decision opportunities.

We can see that the biggest advantage of real option analysis is that it has more choices (L. Q. Chen, 2011). Using the traditional NPV method for project investment 
management is difficult to make a reasonable and reasonable estimate of the market environment decision value and possible future changes of the project. It is easy to have a certain gap among the project risk, the income estimates and the actual situation, and then it will result in short-sighted behavior. By estimating the economic value created by the future decision rights, real options can reasonably estimate the impact of the project on the net present value according to the environmental changes. It avoids the shortcomings of the NPV method and plays an important role in venture capital.

\section{CONCLUSION}

Under the background of rapid development of market economy, with the increasing importance of enterprise project investment risk activities to business development, people have conducted extensive research and discussion on the factors affecting project risk and the methods and tools for assessing project risk, and have gained a deeper understanding of project investment risk management and control. This paper firstly combs the three aspects that mainly affect the investment risk of enterprise projects. According to the current project investment risk management situation, it analyzes from the perspectives of macro market, management mechanism and management team. At the same time, it studies the main evaluation methods of existing project investment risks, and reviews the four methods of sensitivity analysis, break-even point analysis, Monte Carlo simulation and real options, which provides ideas for enterprises to carry out project investment risk management. And reference.

Looking forward to the future, enterprises should pay attention to the control of project investment risks: (1) Improve risk assessment methods and establish risk early warning mechanisms. The environment in which an enterprise is located is affected by many factors, both internal and external. It is more complicated. Therefore, managers and investors need to raise their awareness of risk, and they are highly sensitive and controllable to the complexity and changes of the environment. Enterprises need to establish corresponding risk early warning mechanisms to make timely adjustments to the risks arising from the project investment links. (2) Strengthen the construction of project investment risk management team and introduce risk management and control intermediary institutions. Enterprise investment needs to have a team with professional knowledge and skills to manage, in order to effectively reduce risks and achieve revenue. The use of data and model establishment in risk management have a certain operational difficulty for non-professionals in most enterprises, so companies without professional management team can choose to introduce intermediaries to help accounting and avoid risks. (3) Select a method and model that are reasonably applicable. For the measurement and evaluation methods of the current four investment scenarios, each method has different applicability. When the enterprise selects the investment project and estimates the project risk, it needs to choose according to its own and the project.

\section{REFERENCES}

[1] Keefer, Donald, S. E. Bodily, "Three-Point Approximations fo Continuous Ran Dam Variables," J. Management Science, vol. 29, issue 5, 1983.

[2] Trigeorgis L., "Real Options: Managerial Flexibility and Strategy in Resource Allocation,” Massachusetts: MIT Press, 1996.

[3] C. C. Chang, Y. K. Chen, W. C. Hsu, "A DSAS-Based Minimum Makespan Model for Multi-location Investment Using Fractional Programming," J. The Journal of Risk Analysis and Crisis Response, October 2006. (In Chinese)

[4] Y. Zhang, G. H. Zhou, "Application of Monte Carlo Simulation in Risk Analysis of Investment Projects," J. Shopping Modernization, vol. 519, issue 10, pp. 190, 2007. (In Chinese)

[5] J. Q. Han, "Study on the Risk of Investment Decision and Its Calculation Method," J. Statistics \& Decisions, vol. 351, pp. 91-94, 2012. (In Chinese)

[6] L. W. Zhang, "Risk and Prevention Analysis of Project Investment [J] Investment and Management," vol. 2019, issue 4, pp. 30-31, 2019. (In Chinese)

[7] L. Q. Chen, "Using real option theory to make venture investmen decisions," J. Journal of finance and accounting, vol. 2011, issue 18, pp.57-59, 2011. (In Chinese)

[8] C. Y. Xia, J. Liu, "Application of sensitivity analysis in risk assessment of enterprise investment projects," J. Journal of finance and accounting, vol. 2012, issue 2, pp. 129-131, 2012. (In Chinese)

[9] W. H. Lin, "A Review and Prospect of China's Venture Capital Research,” J. Commercial Accounting, vol. 2018, issue 3, pp. 40-42, 2018. (In Chinese)

[10] B. Wang, "Financial Risk and Risk Control of Investment Projects," J. Finance and Accounting Learning, vol. 2019, issue 10, pp. 55-56, 2019. (In Chinese)

[11] C. Wang. "Research on Comprehensive Evaluation Model of Project Investment Risk Attributes," J. Science and Technology Information, vol. 2006, issue 13, pp. 204-205, 2006. (In Chinese)

[12] J. Zhao, "A brief analysis of investment risk control in enterprise financial management," J. Finance and Economics, vol. 2018, issue 10 pp. 85-86, 2018. (In Chinese)

[13] H. Y. Shen, "Analysis on the Investment Risk of Enterprise Projects," J. Modern Economic Information. vol. 2015, issue 5, pp.88, 2015. (In Chinese) 